\title{
New insights into the roles of cucumber TIR1 homologs and miR393 in regulating fruit/seed set development and leaf morphogenesis
}

\author{
Jian Xu', Ji Li ${ }^{\dagger}$, Li Cui, Ting Zhang, Zhe Wu, Pin-Yu Zhu, Yong-Jiao Meng, Kai-Jing Zhang, Xia-Qing Yu,
} Qun-Feng Lou and Jin-Feng Chen ${ }^{*}$

\begin{abstract}
Background: TIR1-like proteins act as auxin receptors and play essential roles in auxin-mediated plant development processes. The number of auxin receptor family members varies among species. While the functions of auxin receptor genes have been widely studied in Arabidopsis, the distinct functions of cucumber (Cucumis sativus L.) auxin receptors remains poorly understood. To further our understanding of their potential role in cucumber development, two TIRTlike genes were identified and designated CSTIR1 and CSAFB2. In the present study, tomato (Sonanum lycopersicum) was used as a model to investigate the phenotypic and molecular changes associated with the overexpression of CSTIR1 and CSAFB2.

Results: Differences in the subcellular localizations of CSTIR1 and CSAFB2 were identified and both genes were actively expressed in leaf, female flower and young fruit tissues of cucumber. Moreover, CSTIR1- and CSAFB2-overexpressing lines exhibited pleotropic phenotypes ranging from leaf abnormalities to seed germination and parthenocarpic fruit compared with the wild-type plants. To further elucidate the regulation of CSTIR1 and CSAFB2, the role of the miR393/ TIR1 module in regulating cucumber fruit set were investigated. Activation of miR393-mediated mRNA cleavage of CSTIR1 and CSAFB2 was revealed by qPCR and semi-qPCR, which highlighted the critical role of the miR393/TIR1 module in mediating fruit set development in cucumber.

Conclusion: Our results provide new insights into the involvement of CSTIR1 and CSAFB2 in regulating various phenotype alterations, and suggest that post-transcriptional regulation of CSTIR1 and CSAFB2 mediated by miR393 is essential for cucumber fruit set initiation. Collectively, these results further clarify the roles of cucumber TIR1 homologs and miR393 in regulating fruit/seed set development and leaf morphogenesis.
\end{abstract}

Keywords: Auxin receptor, Cucumber, CsTIR1 and CSAFB2, miR393/TIR1 module, Fruit/seed set

\section{Background}

Since the identification of F-box proteins TIR1/AFB (transport inhibitor resistant1/auxin signaling F-box) as auxin receptors $[1,2]$, a $\mathrm{SCF}^{\mathrm{TIR} 1 / \mathrm{AFB}}$-Aux/IAA-ARF signaling module has been well established, which sheds light on the linkage between auxin perception and gene expression [3]. In the absence of auxin, or at low

\footnotetext{
* Correspondence: jfchen@njau.edu.cn

${ }^{\dagger}$ Equal contributors

State Key Laboratory of Crop Genetics and Germplasm Enhancement, Nanjing Agricultural University, Nanjing 210095, China
}

concentrations, ARFs combine with Aux/IAA to form heterodimers; hence, transcription of auxin-responsive genes is not promoted until ARFs are released due to degradation of Aux/IAA by SCF ${ }^{\mathrm{TIR} 1 / \mathrm{AFB}}$-ubiquitin mediated degradation induced by the presence of high auxin levels [4-6]. Thus, auxins act as a "molecular glue" to stimulate the interaction between TIR1/AFB and Aux/IAA [7-9].

As essential regulators of auxin responses in plants, TIR1-like proteins have been identified in various species and are divided into four distinct phylogenetic 
clades TIR1, AFB2 (AFB2/AFB3), AFB4 (AFB4/AFB5) and AFB6. TIR1-like proteins are involved in multiple auxin-responsive biological processes. In Arabidopsis, the TIR1/AFB auxin receptor family comprises six members: TIR1 and five additional AFB proteins $[1,3,10]$. The tirl afb mutants of Arabidopsis exhibit defects in hypocotyl elongation, apical hook, and lateral root formation, leaf morphology and inflorescence architecture [11]. TIR1 and AFB2 act as positive regulators of auxin signaling by mediating auxin-dependent degradation of Aux/IAAs [12, 13]; While, the AFB4 and AFB5 are known to be the major targets of the synthetic auxin, picloram [14, 15], the in vivo roles of AFB1 and AFB3 are still unclear [12].

A similar role for TIR1 in leaf morphogenesis has also been elucidated in tomato and rice plants. Overexpression of SlTIR1 in tomato plants resulted in altered leaf morphology [16], while suppression of OsTIR1 increased the flag leaf inclination angle [17]. The role of TIR1 in fruit and seed development has also analyzed. Phenotypic and molecular analyses indicate that TIR1-like proteins are pivotal regulators of auxins in the fruit set process [16, 18, 19]. Further studies revealed that SITIR1 stimulates stenospermocarpic fruit formation in tomato plants [20]. Although the observation of diverse of degradation behaviors among TIR1/AFB-Aux/IAA complexes suggests that the existence of divergent properties among the TIR1/ $A F B$ genes [13], independent evidence has demonstrated functional redundancy among TIR1/AFB family genes. Loss-of-function analysis by generating higher order mutants in Arabidopsis confirmed that the TIR1/AFB proteins act redundantly to regulate diverse aspects of plant growth and development [11]. Individual knockdown of OsTIR1 or OsAFB2 in rice induced similar leaf morphology at the booting stage [17]. Thus, the mechanisms by which the small family of functionally redundant TIR1-like proteins mediate pleiotropic regulation processes to promote various auxin responses remain to be eucidated.

As the first genome-sequenced vegetable crop, cucumber now serves as a model organism for investigation of the Cucurbitaceae family. Compared with plants belonging to the Cruciferae and Solanaceae families, cucumber has distinct auxin-related developmental processes, such as determinate/indeterminate growth, tendril development and parthenocarpic fruit formation. However, few studies of the TIR1-like gene family of Cucurbitaceae have been reported to date. To gain insights into the roles of cucumber auxin receptors in mediating diverse developmental processes, CsTIR1 and CsAFB2 were cloned and functionally characterized in transgenic tomato plants. In accordance with the concepts of Dharmasiri et al. (2005) and Bian et al. (2012) [11, 17], the functions of CsTIR1 and CsAFB2 were revealed in this study. Further studies indicated that miR393-mediated posttranscriptional regulation of CsTIR1 and CsAFB2 contributes to the fruit set and development processes in cucumber.

\section{Results}

\section{Phylogenetic and polymorphism analysis of CSTIR1/AFB2}

Two genes encoding proteins closely related to the TIR1like gene family of auxin receptors were isolated from cucumber (GenBank ID: GX901282 and GX901283). To investigate their evolutionary relationships with welldefined auxin receptor family proteins of other plant species, a phylogenetic tree was generated using the neighbor-joining approach by MEGA 4.0. Phylogenetic analysis indicated that GX901282 is clustered to the TIR1 clade and has $76.6 \%$ similarity to AtTIR1, while GX901283 belongs to the AFB2 clade and has $75.8 \%$ similarity to VvAFB2 (Fig. 1a; Additional file 1). Thus, the isolated sequences were designated CsTIR1 and CsAFB2 to be consistent with the nomenclature used for the homologs from other plant species. CsTIR1, which encodes a protein of 584 amino acid residues, contains an F-box region and six leucine-rich repeat (LRR) domains, while CsAFB2 encodes a protein of 587 amino acid residues and comprises an Fbox region and seven LRR domains (Fig. 1b).

\section{Subcellular localizations of CsTIR1/AFB2 proteins}

To determine the subcellular localization of CsTIR1 and CsAFB2 proteins, the CsTIR1-GFP and CsAFB2GFP fusion proteins were transiently expressed in onion epidermal cells using gene gun bombardment. Laser confocal scanning of protein fluorescence revealed that the green fluorescence signal of GFP alone was detected throughout the cell (Fig. 2a), in accordance with the expected cytosolic localization of the GFP protein. Interestingly, the fluorescence of CsTIR1-GFP was not only detected in nucleus but also detected in cytolemma (Fig. 2b), that is inconsistent with Ren's result [16]. The green fluorescence signal of CsAFB2-GFP was detected in the nucleus (Fig. 2c).

\section{Expression patterns of CsTIR1/AFB2 in cucumber}

Temporal and spatial transcriptional characteristics of CsTIR1 and CsAFB2 were investigated by qRT-PCR. Both CsTIR1 and CsAFB2 were detected in all the major organs of cucumber plants including root, stem, leaf, female/male flowers and young fruit. These two genes showed similar expression patterns, with the highest abundance in leaf and female flower tissues and relatively low mRNA levels in roots and young fruit (Fig. 3a, b). The phytohormones responses of CsTIR1 and 


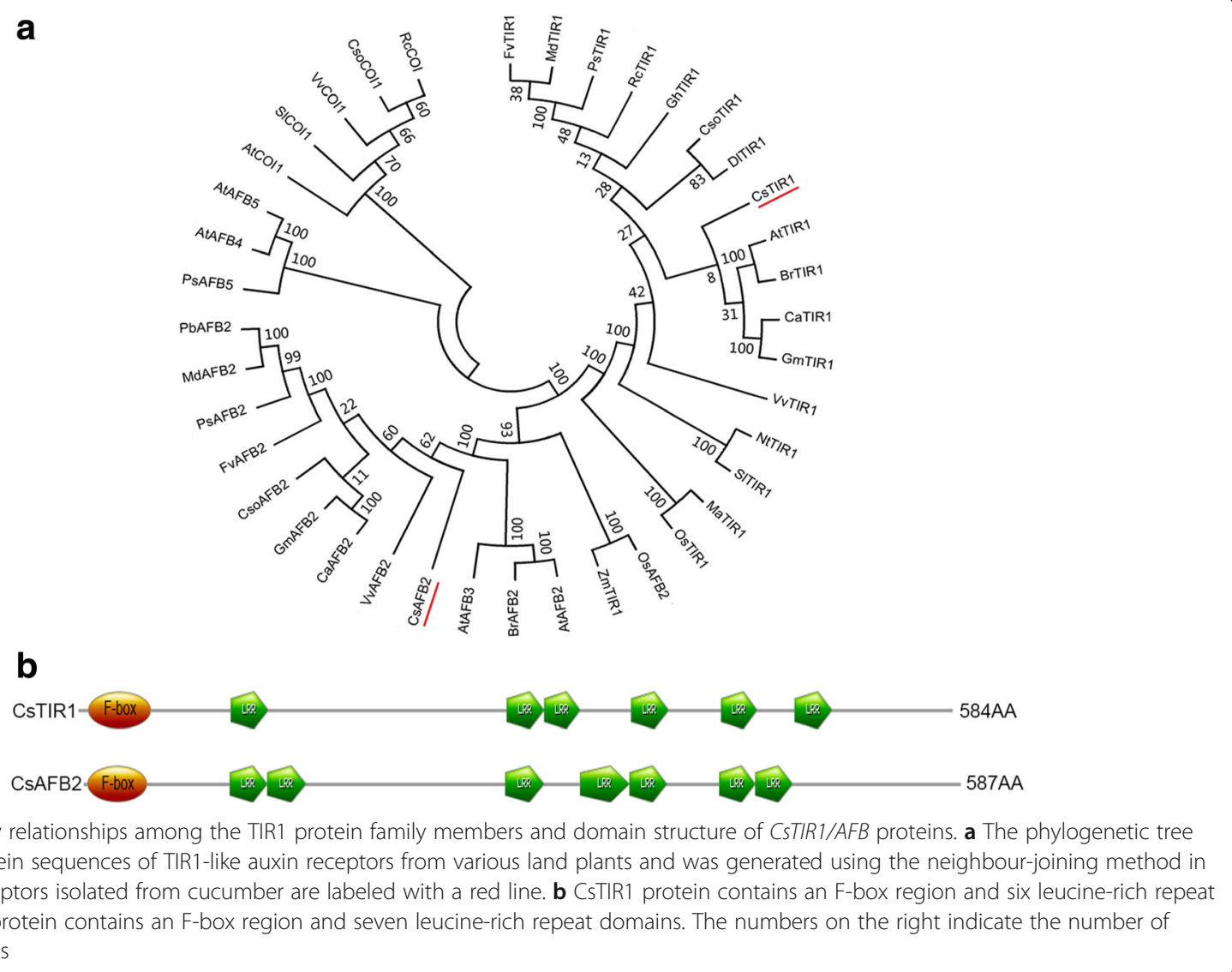

CsAFB2 were investigated in exogenous hormone treatment experiments. qRT-PCR analysis showed that the transcription of CsTIR1 was sensitive only to low $(5 \mu \mathrm{M}$ NAA) and medium (10 $\mu \mathrm{M}$ NAA) auxin concentrations (Fig. 3c). In contrast, CsAFB2 expression was upregulated by exogenous gibberellins, cytokinin and auxin (Fig. 3d).

Treatment of cucumber ovaries (0dpa) with high concentrations of exogenous auxin $(500 \mu \mathrm{M})$, cytokinins $(400 \mu \mathrm{M})$, gibberellins $(3000 \mu \mathrm{M})$ and brassinosteriod $(0.2 \mu \mathrm{M})$ stimulated parthenocarpy. Interestingly, analysis of hormone-treated ovaries showed that expression of CsTIR1 and CsAFB2 was downregulated in the auxinand cytokinins- induced parthenocarpic fruit as well as in the fruit set by pollination, while expression of the two genes was upregulated in gibberellin- and brassinosteriod-induced parthenocarpic fruit (Fig. 3e, f).

\section{Functional analysis of CsTIR1 and AFB2 genes}

To assess the physiological importance of the cucumber auxin receptor proteins, homozygous transgenic Solanum lycopersicum, cv. Micro-Tom lines overexpressing CsTIR1 and CsAFB2 were generated (designated CsTIR1-OE and CsAFB2-OE, respectively). qRT-PCR analysis showed that CsTIR1 and CsAFB2 were expressed abundantly in transgenic lines, with almost no effect on endogenous SITIR1 expression (Additional file 2 ). For each of the two genotypes, one of the most highly upregulated transgenic lines was selected for further characterization. Pleiotropic phenotypes were observed in these tomato lines (Table 1). Compact stature was the most intuitionistic alteration in the transgenic plants (Fig. 4a), which was consistent with the effects of transgenic expression of SlTIR1 and PSITIR1 [16, 19]. Compared with CsAFB2-OE lines, CsTIR1-OE lines exhibited reduced plant height phenotype (Fig. 4a). Distorted leaf growth resulted in severely inward curling growth status in transgenic lines (Fig. 4a, b).

Both the CsTIR1 and the CsAFB2 overexpression lines exhibited a convex leaf surface phenotype, compared with the smooth leaf surface of wild-type (WT) plants. Although overexpression of SITIR1 has been reported to increase trichrome numbers [16], no changes in the morphology and number of trichomes were observed in the leaves of CsTIR1-OE and CsAFB2-OE transgenic tomato plants. Surprisingly, CSTIR1 overexpression reduced stomata formation, while the number was significantly reduced by CsAFB2 overexpression (Fig. 4c). Expression analysis of related genes strongly indicated that the ARF10 protein functions as a transcriptional 


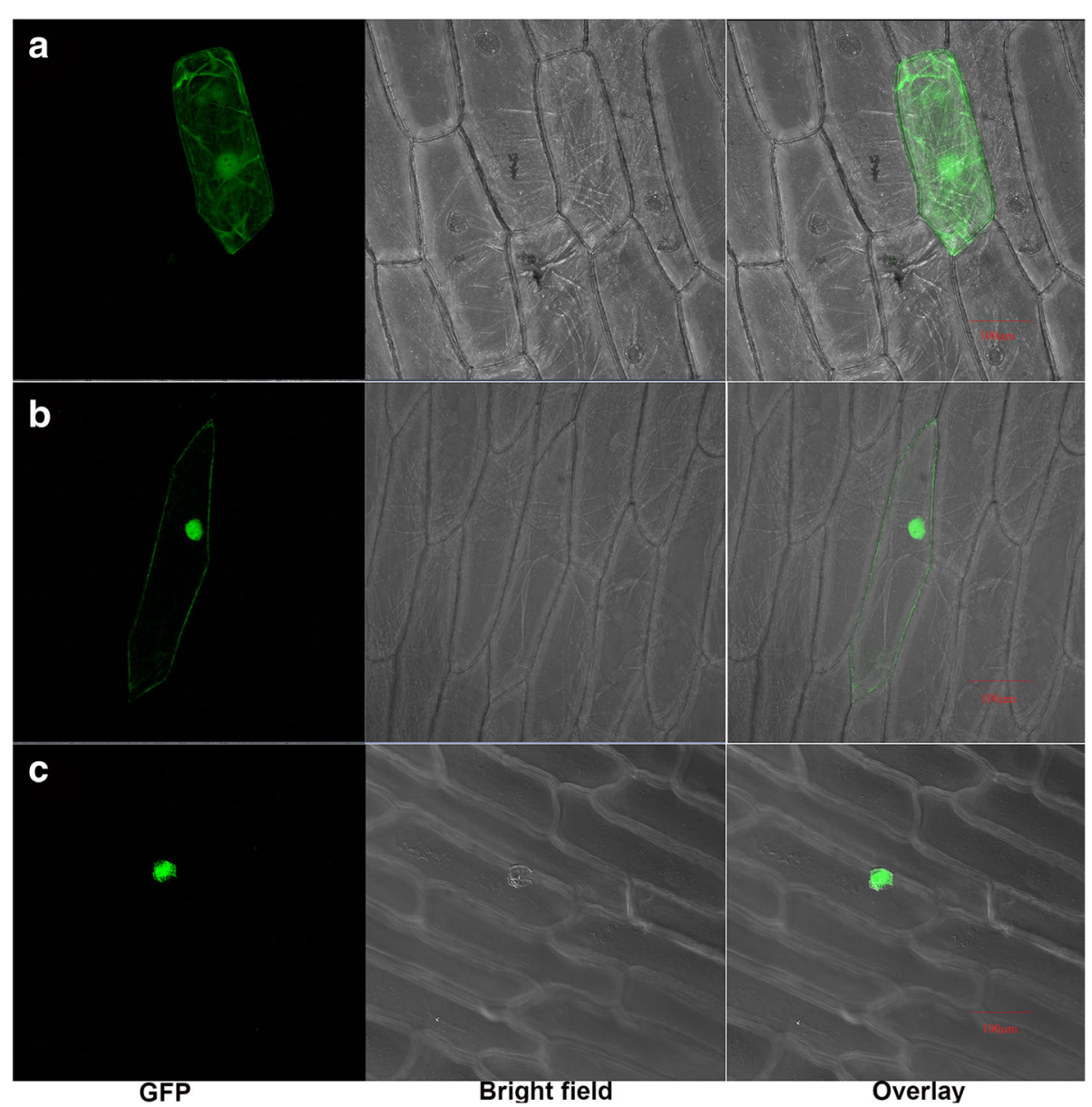

Fig. 2 Subcellular localization of CSTIR1 and CSAFB2 in onion epidermal cells. Control plasmid (GFP) and fusion vector constructs (CSTIR1-GFP, CSAFB2-GFP) were transformed separately into onion epidermal cells by microprojectile bombardment. a Subcellular localization of GFP alone. $\mathbf{b}$ Subcellular localization of the CSTIR1-GFP fusion protein. c Subcellular localization of the CsAFB2-GFP fusion protein. All proteins were analyzed by laser scanning confocal fluorescence microscopy (GFP). Light micrographs (Bright field) and fluorescence (GFP) images are merged (Overlay) to illustrate the different location of the three proteins. Scale bars $=100 \mu \mathrm{m}$

repressor of leaflet lamina outgrowth [21], while $\mathrm{SPCH}$ and MUTE were found to be involved in the stomata differentiation process [22, 23]. qRT-PCR analysis showed that SIARF10 was upregulated in transgenic lines and was implicated as a positive regulator of leaf morphology. Furthermore, SISPCH and SIMUTE were upregulated in CsAFB2-OE lines but down-regulated in CsTIR1-OE lines (Fig. 4d).

Overexpression of CsTIR1 and CsAFB2 resulted in reduced seed size (Fig. 5a) and fewer seeds in each fruit (Fig. 5b). Further investigations of germination properties showed that the seed germination potential was significantly reduced in transgenic lines (Fig. 5c). To assess the molecular mechanisms underlying these alterations, the expression of AP-like (determiner for seed size in Arabidopsis [24]), STK (a maternal role in fertilization and seed development and related to seed number [25]), GIGANTEA and ELIP (involved in the seed germination process [26]) were investigated. Expression analysis revealed that SIAP-like, SISTK and SIGIGANTEA were downregulated in the transgenic lines, while SIELIP was upregulated (Fig. 5d).

Although transcription analysis showed that CsTIR1 and CsAFB2 were downregulated during both the pollination and parthenocarpic fruit set processes, emasculation experiments suggested that overexpression of CsTIR1 or CsAFB2 induced facultative parthenocarpy in tomato fruit (Fig. 6a, b; Table 1). Seedless fruit phenotypes were also observed in both the CsTIR1-OE and CsAFB2-OE lines (Fig. 6c). Ovary expansion prior to anthesis may be the cause of seedlessness fruit phenotype (Fig. 6b). The CsAFB2-OE lines exhibited more obvious negative effects on seed set than the CSTIR1-OE lines because of the exposed stigma phenotype (Fig. 6a, e). Moreover, elongated fruit shape was induced by CsAFB2 (Fig. 6d; Table 1). 


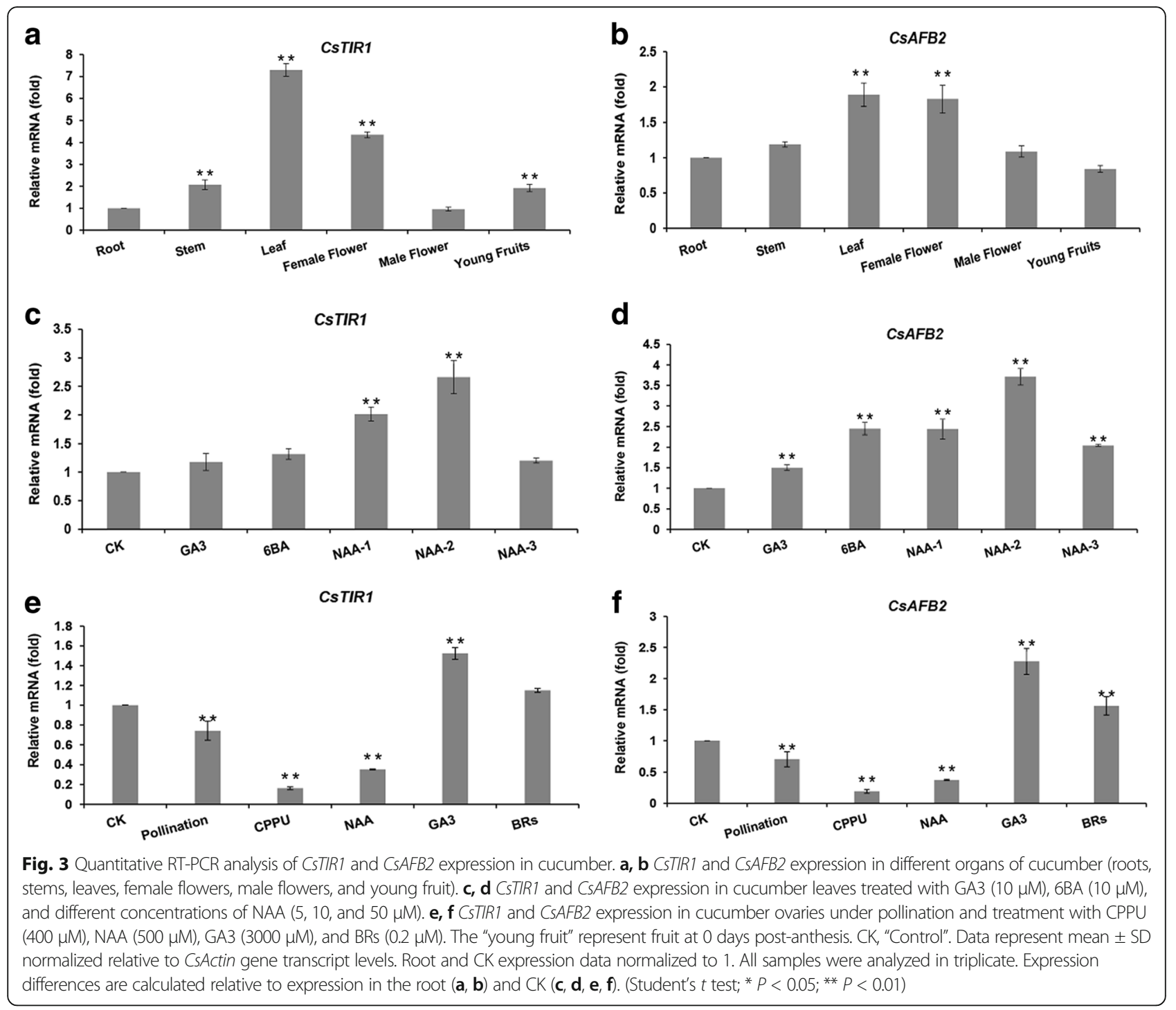

More detailed information about the phenotypes of CsTIR1-OE and CsAFB2-OE transgenic tomato plants is shown in Table 2.

\section{Investigation of post-transcriptional regulations of CsTIR1/ AFB2 via miR393}

Previous studies have demonstrated that miR393 plays a role in the regulation of TIR1/AFB expression [12, 27]. Despite the roles of miR393 and its target genes in multiple biological processes, much remains to be clarified about the function of miR393 and the miR393/TIR1 homologs module in regulating cucumber fruit set and development. MiR393 expression levels were analyzed in different early fruit developmental stages (Fig. 7). In parthenocarpic fruit, miR393 expression remained relatively stable, especially from 0 to $3 \mathrm{dpa}$ (Fig. 7a), while in nonparthenocarpic fruit, miR393 expression was relatively low before anthesis but increased dramatically at the point of anthesis (0dpa). When the ovaries were pollinated manually (pollination induced fruit set), miR393 expression decreased rapidly to the low level detected in the immature ovaries $(-3,-2,-1 \mathrm{dpa})$. Although miR393

Table 1 Summary of phenotypes in transgenic tomato plants overexpressing CsTIR1 and CsAFB2

\begin{tabular}{lll}
\hline Genotype & Line number & Phenotype \\
\hline $35 S-C S T I R 1$ & L1-L4 & $\begin{array}{l}\text { Severely dwarf plants, abnormal leaves, suppressed seed size and germination activity, splited staminal cone, precocious } \\
\text { fruit set prior to anthesis, reduced seed number/per fruit, parthenocarpic fruit set }\end{array}$ \\
35S-CSAFB2 & L1-L2 & $\begin{array}{l}\text { Compact stature of plants, abnomal leaves, suppressed seed size and germination activity, splited staminal cone, } \\
\text { precocious fruit set prior to anthesis, altered fruit shape, reduced seed number/per fruit, parthenocarpic fruit set }\end{array}$ \\
\hline
\end{tabular}



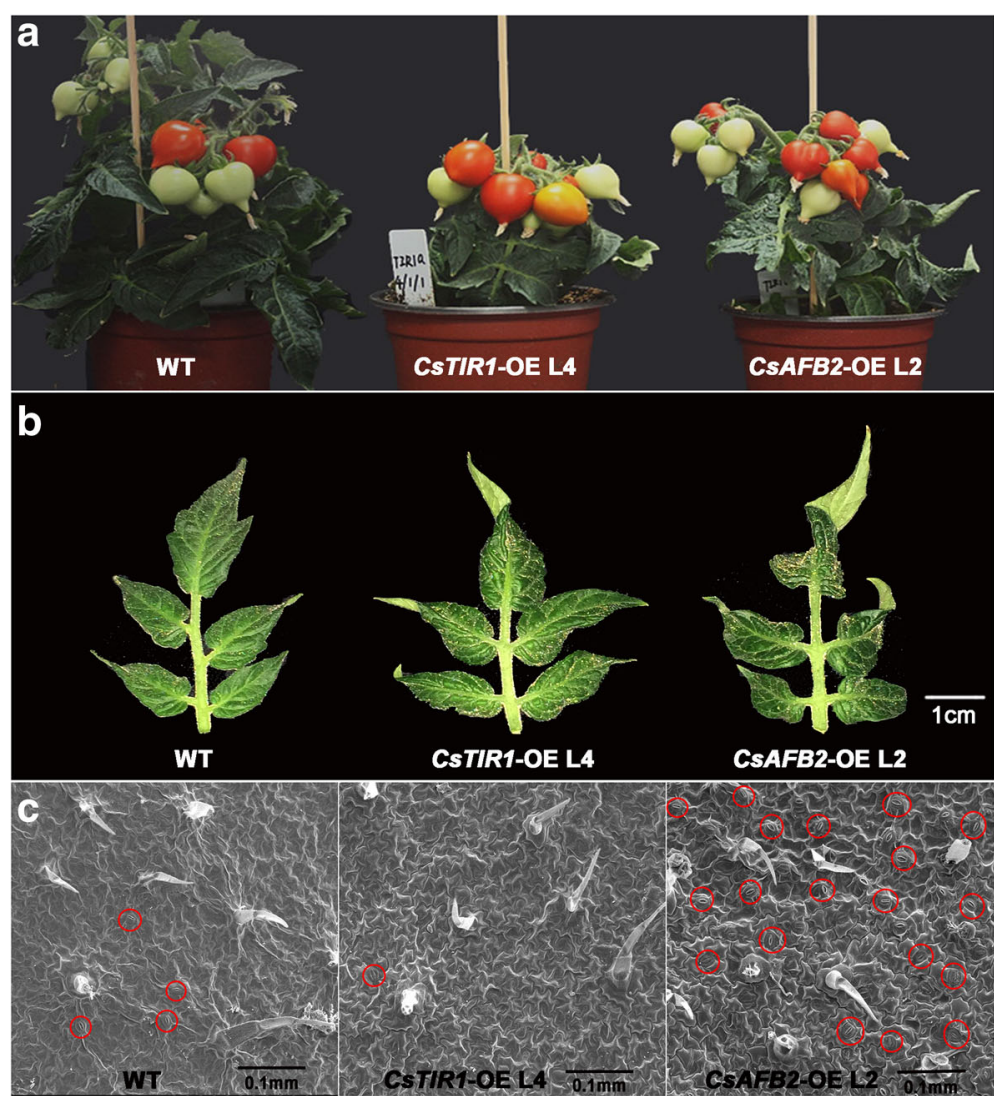

d
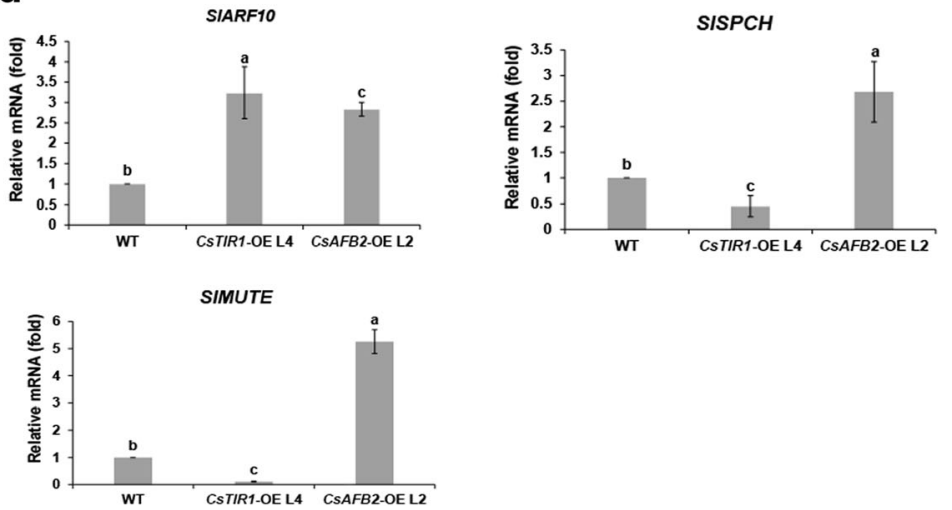

Fig. 4 Vegetative growth and leaf architecture phenotypes in wild-type and transgenic plants. a Both CSTIR1-OE L4 and CSAFB2-OE L2 exhibited compact stature, and CSTIR1-OE L4 exhibited a severely dwarfed phenotype compared with the wild-type (WT). b Leaves of both CSTIR1-OE L4 and CSAFB2-OE L2 exhibited distorted growth behavior. Scale bar $=1 \mathrm{~cm}$. c Leaf surface of WT, CSTIR1-OE L4, and CSAFB2-OE L2 observed by scanning electron microscopy. Transgenic line leaf surfaces were convex compared with the WT. Stomata are labeled with red circles. Scale bar $=0.1 \mathrm{~mm}$. d Quantitative PCR analysis of transcript accumulation of SIARF10, SISPCH, and SIMUTE. Expression of SIARF10, SISPCH, and SIMUTE in the WT was normalized to 1. Data represent mean \pm SD of three biological replicates. Different letters above bars indicate significant differences among different genotypes (Student's $t$-test, $P<0.05$ )

expression was also downregulated in abortive fruit (bagging treatment), it was $2-4$-fold higher relative to that in the pollinated fruit (Fig. 7b).

In cucumber, CsTIR1 has three nucleotide mismatches in the miR393 recognition site, while CsAFB2 contains two mismatches, which are thought to cause different effects on miR393-directed mRNA cleavage (Fig. 8a). This suggests that CsTIR1 and CsAFB2 are regulated by miR393 in a post-transcriptional manner. To investigate miR393-mediated post-transcriptional regulations of CsTIR1/AFB2 during the fruit set process, four pairs of specific primers were designed for the detection of full- 


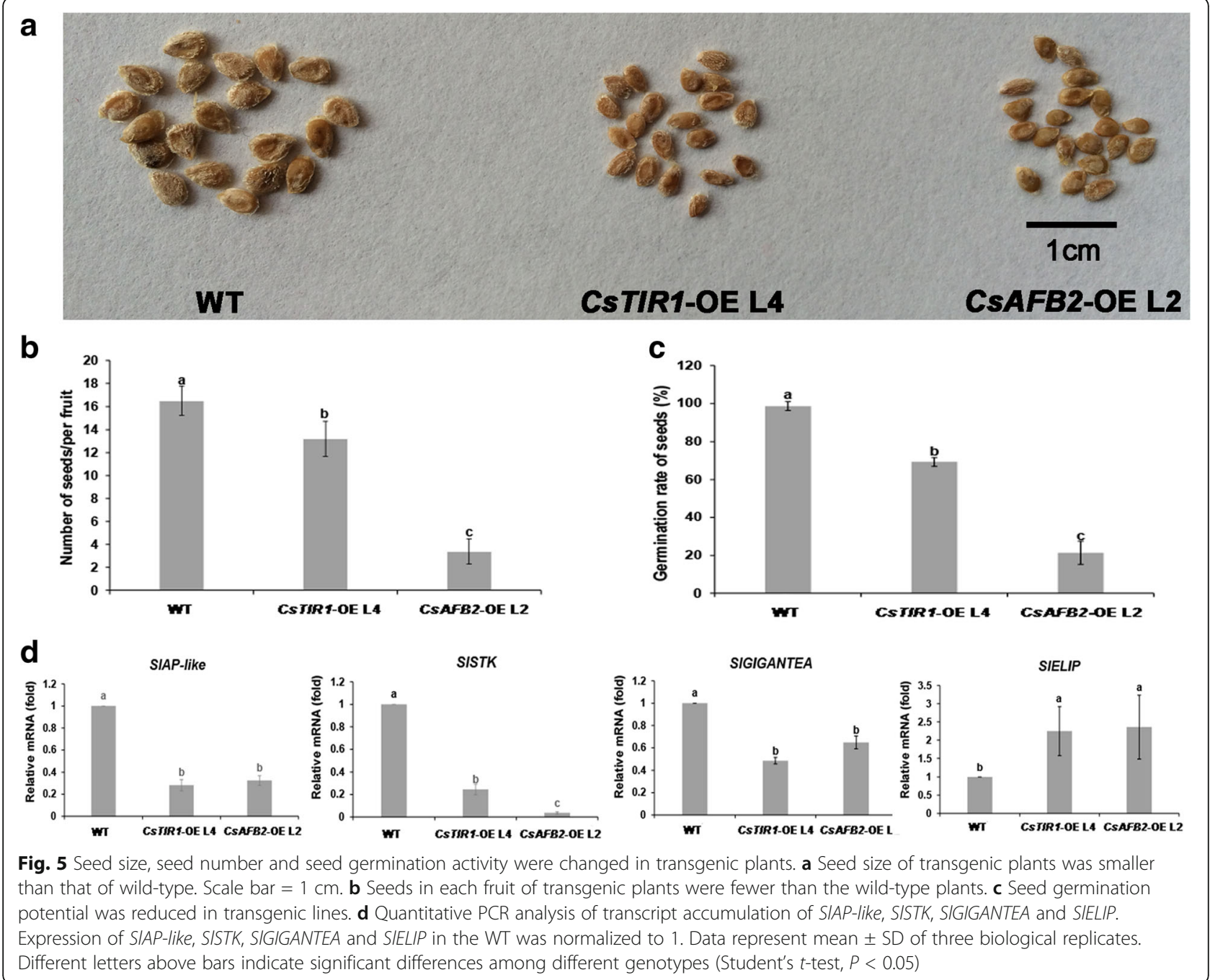

length transcripts (complete fragments) and total mRNA (complete fragments and alternative splicing fragments) of CsTIR1 and CsAFB2 (Fig. 8a; Additional file 3).

Both the total and full-length mRNA transcripts of CsAFB2 were much less abundant than those of CsTIR1, and the full-length mRNA of CsAFB2 was barely detected during these fruit developmental processes. The total transcripts of CsTIR1 and CsAFB2 reached the highest expression levels at Odpa, while only low levels of the full-length transcripts of these genes were detected (Fig. 8b). In accordance with this, qRT-PCR analysis showed that miR393 expression peaked at anthesis (Fig. 7b), indicating that miR393-mediated cleavage of CsTIR1 and CsAFB2 was active during flowering (0dpa). Despite the relatively low miR393 expression levels, some full-length mRNA was detected in both pollinated and parthenocarpic fruit set (Figs. 7 and 8b). Interestingly, although the miR393 levels in abortive fruit were relatively higher than those of set fruit (Fig. 7b), there was almost no degradation of full-length mRNA of CsTIR1 in abortive fruit (Fig. 8b).

\section{Discussion}

As a reference species for Cucurbitaceae crops, cucumber exhibits various traits that may be regulated by various auxin gene networks. However, few auxin signaling transduction components of cucumber have been studied. To investigate the exact molecular mechanisms underlying the functions of cucumber auxin receptors in plant growth and fruit development, both CSTIR1 and CSAFB2 genes were isolated and the physiological and molecular consequences of their overexpression in tomato plants were evaluated.

In Arabidopsis, six auxin receptors have been identified, comprising AtTIR1 and its closest paralogs AFB1- AFB5 [10]. In tomato plants, three F-box receptor members have been identified [16], while three TIR1-like auxin receptors were found in plum [19] and there are six TIR1/ 


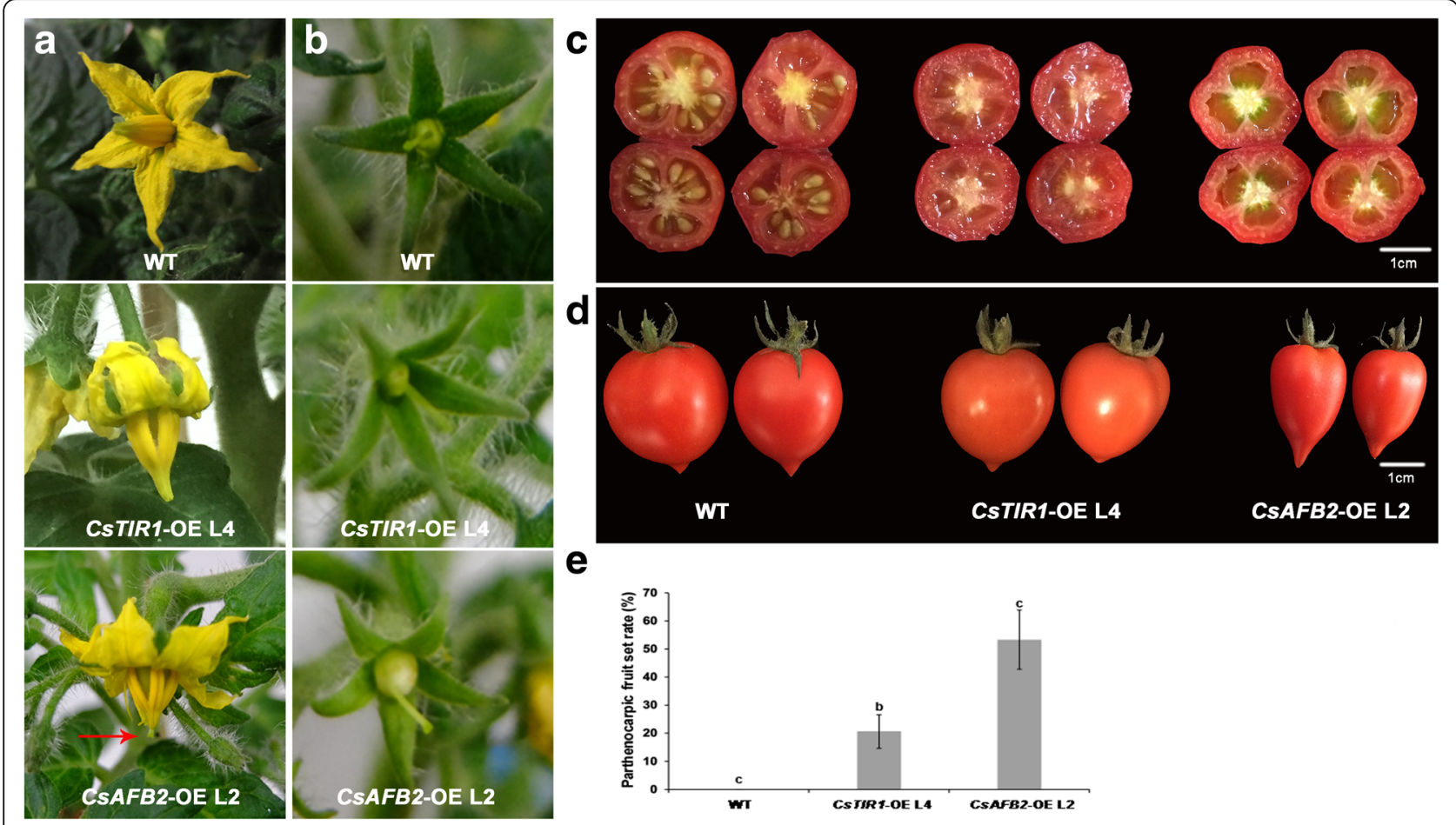

Fig. 6 Fruit set and parthenocarpy in transgenic plants. a Flowers at anthesis day in wild-type and transgenic plants. Both CSTIR1-OE L4 and CSAFB2-OE L2 exhibited ovary expansion prior to anthesis, and splited staminal cone. The exposed stigma of CSAFB2-OE L2 is labeled with red arrow. b Ovaries of transgenic lines were successfully set fruit and expansion after emasculation. c Wild-type seeded fruit and transgenic parthenocarpic fruit. Scale bar $=1 \mathrm{~cm}$. $\mathbf{d}$ Altered fruit shape was observed in the CSAFB2-OE L2. Scale bar $=1 \mathrm{~cm}$. e Comparison of parthenocarpic fruit set rate among wild-type, CSTIR1-OE L4, and CSAFB2-OE L2 plants. Data represent mean \pm SD of three biological replicates with more than twenty fruits for each replicate. Different letters above bars indicate significant differences among different genotypes (Student's $t$-test, $P<0.05$ )

AFBs homologs in the rice genome [17]. In Populus, eight TIR1 homologous genes (PtrFBLs) were identified [28]. However, only two auxin receptors belonging to the F-box TIR1-like gene family have been identified in cucumber $[29,30]$. Cucumber has a small genome with few tandem duplications [31]. Previous studies have shown that evolutionary momentum is basically facilitated by genome duplication events, which are thought to occur frequently during the evolution of organism $[32,33]$. Therefore, it is tempting to speculate that the small number of TIR1 homologs in cucumber is probably due to the absence of recent whole-genome duplications.

TIR1/AFBs show auxin-insensitive transcriptional characteristics in Arabidopsis and Populus [12, 28]. Similarly, limited responses of CsTIR1 to NAA treatment were also detected in cucumber, although CsAFB2

Table 2 Phenotypes of wild-type (WT), CSTIR1-overxpressing (CSTIR1-OE) and CSAFB2-overexpressing (CSAFB2-OE) transgenic tomato plants

\begin{tabular}{|c|c|c|c|c|c|c|c|}
\hline parameter & WT & CsTIR1-OE L1 & CsTIR1-OE L2 & CSTIR1-OE L3 & CSTIR1-OE L4 & CSAFB2-OE L1 & CSAFB2-OE L2 \\
\hline Plant height (one month old, cm) & $8.8 \pm 0.2 a$ & $4.2 \pm 0.3 f$ & $4.6 \pm 0.2 e$ & $5.4 \pm 0.1 d$ & $4.2 \pm 0.2 f$ & $6.1 \pm 0.3 c$ & $6.5 \pm 0.1 b$ \\
\hline Plant height (three month old, cm) & $20.5 \pm 1.1 a$ & $9.4 \pm 1.1 \mathrm{c}$ & $9.9 \pm 0.6 c$ & $8.6 \pm 0.9 c$ & $8.2 \pm 1.1 \mathrm{c}$ & $13.6 \pm 1.2 b$ & $12.3 \pm 1.2 b$ \\
\hline Length of seed (mm) & $4.4 \pm 0.4 a$ & $3.0 \pm 0.2 b$ & $3.1 \pm 0.4 b$ & $3.2 \pm 0.2 b$ & $3.2 \pm 0.4 b$ & $3.3 \pm 0.3 b$ & $3.3 \pm 0.2 b$ \\
\hline Width of seed (mm) & $2.8 \pm 0.3 a$ & $1.5 \pm 0.2 b$ & $1.6 \pm 0.2 b$ & $1.5 \pm 0.2 b$ & $1.5 \pm 0.2 b$ & $1.5 \pm 0.2 b$ & $1.6 \pm 0.2 b$ \\
\hline Seeds per fruit (n) & $16.5 \pm 1.3 a$ & $13.1 \pm 1.4 b$ & $13 \pm 1.3 b$ & $12.9 \pm 1.4 b$ & $13.2 \pm 1.5 b$ & $3.5 \pm 1.2 \mathrm{C}$ & $3.4 \pm 1.1 c$ \\
\hline Seeds germination rate (\%) & $98.7 \pm 2.3 \% a$ & $72 \pm 6.9 \% b$ & $70.6 \pm 2.3 \% b$ & $72 \pm 6.9 \% b$ & $69.3 \pm 2.3 \% b$ & $25.3 \pm 4.6 \% c$ & $21.3 \pm 6.1 \% c$ \\
\hline Parthenocarpic fruit set rate (\%) & Oc & $20.8 \pm 6.7 \% b$ & $19.7 \pm 5.9 b$ & $19.6 \pm 5.5 \% b$ & $20.6 \pm 5.9 \% b$ & $51.3 \pm 11.0 \% a$ & $53.3 \pm 10.5 \% a$ \\
\hline Horizontal diameters of fruit (cm) & $2.1 \pm 0.2 \mathrm{a}$ & $2.0 \pm 0.2 b$ & $1.8 \pm 0.2 b$ & $1.9 \pm 0.1 b$ & $1.9 \pm 0.2 b$ & $1.4 \pm 0.1 c$ & $1.4 \pm 0.1 c$ \\
\hline Vertical diameters of fruit (cm) & $3.3 \pm 0.1 a$ & $2.8 \pm 0.1 c$ & $2.9 \pm 0.1 b c$ & $2.9 \pm 0.1 b c$ & $2.9 \pm 0.1 b c$ & $3.0 \pm 0.1 b$ & $3.0 \pm 0.1 b$ \\
\hline
\end{tabular}

Values are means of 5-10 plants, \pm SE. The statistical significance of mean differences was analyzed using Student's $t$-test, $P<0.05$ 


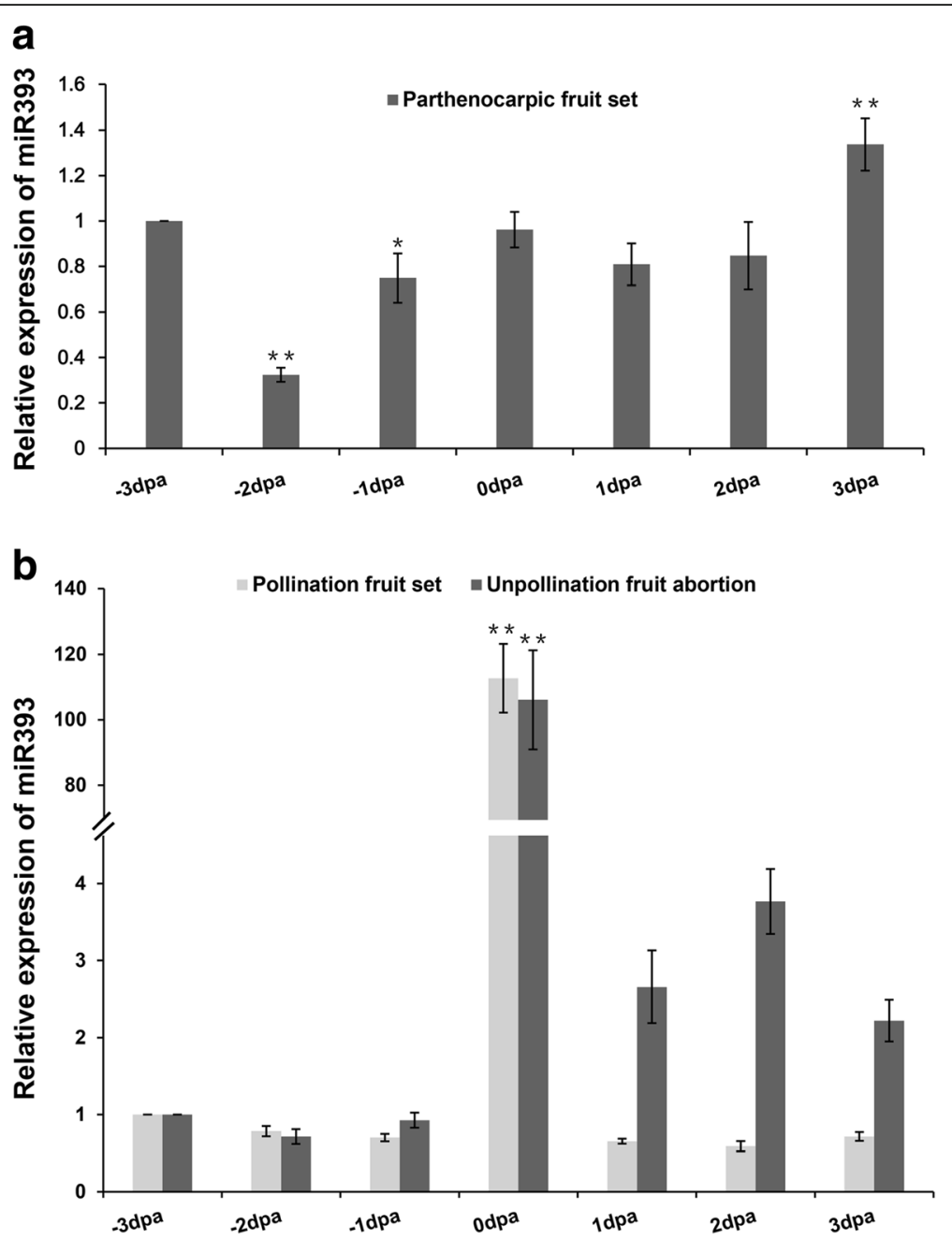

Fig. 7 Expression analysis of miR393 during early stages of cucumber fruit development. a Relative expression of miR393 during the early stages of parthenocarpic fruit set development ( $-3 \mathrm{dpa}$ to $3 \mathrm{dpa}$ ). dpa: days post-anthesis. b Relative expression of miR393 during the early stages of pollinated fruit set formation and unpollinated fruit abortion ( $-3 \mathrm{dpa}$ to $3 \mathrm{dpa}$ ). Expression of miR393 in $-3 \mathrm{dpa}$ fruit was normalized to 1. Data represent mean $\pm \mathrm{SD}$ of three biological replicates. (Student's $t$-test; ${ }^{*} P<0.05 ;{ }^{* *} P<0.01$ )

showed sensitive responses to various exogenous phytohormones treatments (Fig. 3c, d). As intranuclear auxin receptors, TIR1/AFB proteins generally perform their functions within the nucleus $[1,16,34]$. However, subcellular localization analysis showed that cucumber CsTIR1 proteins were present not only in the nucleus but also on the cell membrane (Fig. 2b). Thus, the potential function of CsTIR1 as a membrane receptor deserves further investigation.

A series of studies suggested that the TIR1 protein may have a parallel function in leaf architecture and fruit development. Overexpression of SITIR1 results in pleiotropic phenotypes in tomato plants, including parthenocarpic fruit formation and leaf morphology [16]. El-Sharkawy demonstrated the critical role of PslTIR1 as a positive regulator of auxin signaling in coordinating the development of leaves and fruit [19].
Furthermore, knockdown of either OsTIR1 or OsAFB2 altered the flag leaf inclination angle [17]. In this study, the highest transcription levels of CsTIR1 and CsAFB2 were in leaves and female flowers (Fig. 3a, b). Overexpression of the cucumber TIR1-like proteins induced curved growth of leaves and abnormal fruit expansion (Fig. 4a, b and 6a, b). Previous studies showed that trichome development is also regulated by TIR1 proteins [16]; however, no obvious alterations in trichome numbers and morphology were observed in the CsTIR1-OE and CsAFB2-OE transgenic lines. In addition, both the CsTIR1-OE and CsAFB2-OE lines exhibited decreased seed germination potential (Fig. 5c). Down-regulation of SlGIGANTEA in the transgenic lines is consistent with its positive role in the promotion of germination under continuous $\mathrm{R}$ in tomato seeds revealed in a previous study [35]. 


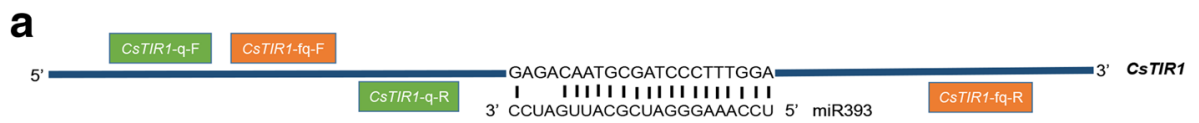

3. CCUAGUUACGCUAGGGAAACCU 5' miR393

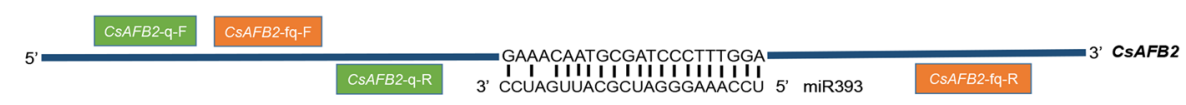

b
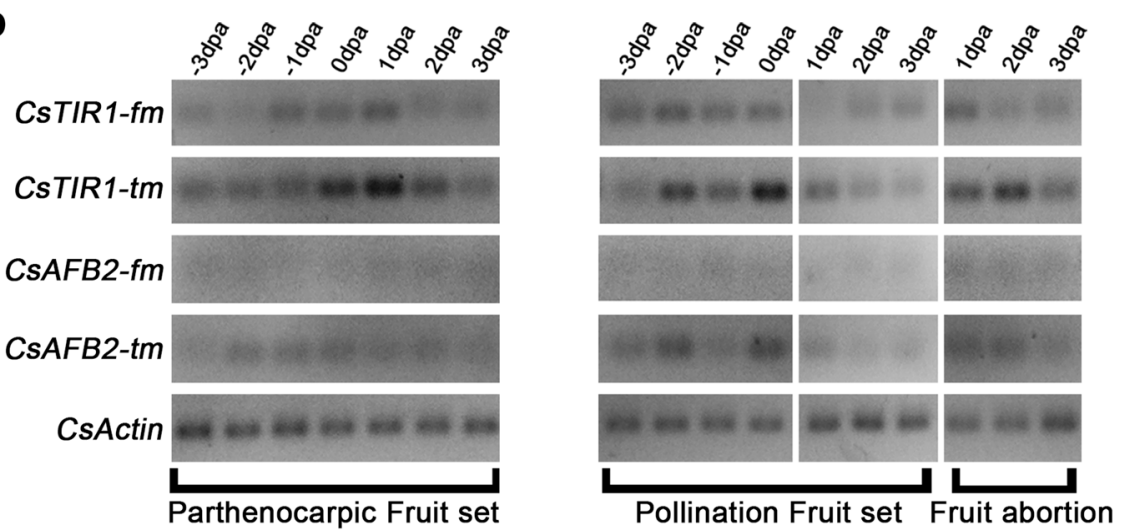

Fig. 8 Expression analysis of full-length transcripts and total transcripts of CSTIR1 and CSAFB2 during the cucumber parthenocarpic fruit set, pollination fruit set and fruit abortion processes. a Schematic diagram of specific primer location. CsTIR1 has three nucleotide mismatches in the miR393 recognition site, while CSAFB2 contains two mismatches in the miR393 recognition site. The orange pair of primers separated on both sides of the miR393-cleavage site were used to detect the full-length transcripts of CSTIR1 and CSAFB2. The green pair of primers distributed on one side of the miR393-cleavage site were used for detection of total transcripts of CSTIR1 and CSAFB2. b Semi-quantitative RT-PCR analysis of full-length transcript and total transcript accumulation of CSTIR1 and CSAFB2 during the early stages of the cucumber parthenocarpic fruit set, pollination fruit set and fruit abortion processes ( $-3 \mathrm{dpa}$ to $3 \mathrm{dpa}$ ). dpa: days post-anthesis. fm: full-length mRNA (complete fragments); tm: total mRNA (complete fragments and alternative splicing fragments)

Furthermore, SIELIP, which has been reported to be significantly increased by inhibition of seed germination [26], was found to be upregulated in the transgenic lines. Thus, these observations indicate auxin receptor overexpression in tomato plants alters the expression of genes involved in seed germination process. Considering that silence of AtTIR1 could also repress seed germination activity [1], therefore, it can be speculated that transcriptional balance of TIR1 family genes is essential for seed germination.

Independent evidence suggests that TIR1/AFB proteins function as redundant auxin receptors, collectively mediating auxin-regulated responses throughout plant growth and development. Different phenotypes induced by overexpression of CsTIR1 and CsAFB2 were revealed in this study. CsTIR1 and CsAFB2 were found to have opposing regulatory functions in controlling the number of stomata, with CsTIR1 overexpression inhibiting stomata formation, while stomata numbers were significantly increase by CsAFB2 overexpression (Fig. 4c). Interestingly, CsTIR1-OE and CsAFB2-OE overexpression resulted in similarly opposing patterns of SISPCH and SIMUTE expression (Fig. 4d), suggesting that overexpression of CsTIR1 and CsAFB2 has different effects on expression of stomata differentiation-related genes, thereby causing the opposite phenotypes in terms of stomata number. Furthermore, CsAFB2-OE lines exhibited higher parthenocarpic fruit set rates and altered fruit shape compared with the CsTIR1-OE lines. Studies have indicated that co-receptor complexes formed by different combinations of TIR1/AFB and the Aux/IAA proteins have a wide range of auxin-binding affinities $[12,28,36]$. We speculate that this accounts for the differences in auxin-related phenotypes, including alterations in leaf architecture and fruit development that are induced by CsTIR1 and CsAFB2 overexpression.

The roles of the miR393/TIR1 homolog module in regulating root growth, leaf inclination, tillering, disease resistance and salt tolerance have been well characterized. In Arabidopsis, regulation of auxin response by miR393-targeted TIR1 is involved in normal development [37], and the nitrate-responsive miR393/AFB3 regulatory module controls the root system architecture [36]. In addition, the miRNA393/TIR1 homolog module influences flag leaf inclination, crown root initiation, seminal root development and tillering in rice [17, 38]. Moreover, miR393-guided cleavage of TIR1, AFB2, and AFB3 transcripts enhances innate immunity in response 
to bacterial and fungal infection in leaves [27, 39]. Downregulation of OsTIR1 and OsAFB2 via OsmiR393 led to reduced tolerance to salt and drought in rice [40]. In contrast, overexpression of a miR393-resistant form of mTIR1 enhanced salt tolerance in Arabidopsis [41]. However, less is known about the role of the miR393/ TIR1 homolog module in the stages of fruit development. In this study, we also explored the mechanism by which the miR393/TIR1 homolog module regulates cucumber fruit development. We found that miR393regulates the degradation of CsAFB2 in all types of fruit development, with total degradation of full-length transcripts of CsAFB2 detected regardless of the process of parthenocarpic or pollinated fruit development or fruit abortion. Although miR393 expression levels were extremely high at anthesis, some full-length CsTIR1 remained undegraded, probably due to the enrichment of CSTIR1 transcripts or the incomplete cleavage of the miR393 target, CsTIR1. More interestingly, cleavage of CsTIR1 was complete in 1dpa pollinated fruit, while there was no cleavage in 1dpa abortive fruit, in which even the miR393 level was much higher than that in the pollinated fruit (Fig. $8 \mathrm{~b}$ ). These findings provide an indication that the divergent functions of CsTIR1 and CsAFB2 are induced by the differences in cleavage regulation by miR393; however, the differences in miR393-mediated regulation of CsTIR1 and CsAFB2 cleavage remain to be verified through in vivo.

\section{Conclusion}

This study was focused on the identification of distinct functions of cucumber TIR1-like genes. We identified and cloned both members of this gene family in cucumber. We demonstrated the differences in subcellular localizations of CsTIR1 and CsAFB2 proteins and analysis of CsTIR1 and CsAFB2 expression indicated their involvement in leaf morphogenesis and the fruit set process in cucumber. The roles of CsTIR1 and CsAFB2 in these processes were further revealed by the analysis of overexpressing lines. Moreover, qPCR and semi-qPCR results support the hypothesis that the miR393/TIR1 module participates in the cucumber fruit set process. These findings further clarify the functions of cucumber auxin receptors and provide new insights into the role of cucumber TIR1 homologs and miR393 in regulating fruit/seed set development and leaf morphogenesis.

\section{Methods}

\section{Plant materials and growth conditions}

Two cucumber breeding lines, parthenocarpic line 'EC1' and non-parthenocarpic line '8419 s-1', were grown in greenhouses during the natural growing season $(12 \mathrm{~h}$ photoperiod, $29 / 17{ }^{\circ} \mathrm{C}$ average day/night temperature, $85 \%$ humidity, $800 \mu \mathrm{molm}^{-2} \mathrm{~s}^{-1}$ ) at Nanjing Agricultural
University (China). Both 'EC1' and ' 8419 s-1' were breeding materials of the Nanjing Agricultural University. Tissues (root, stem, leaf, female flower, male flower and ovary) were collected from 9-week-old ' $8419 \mathrm{~s}-1$ ' plants. For hormone treatment analysis, the leaves of ' $8419 \mathrm{~s}-1$ ' plants $\left(n=30\right.$ per group) were treated with $\mathrm{GA}_{3}$ $(10 \mu \mathrm{M}), 6-\mathrm{BA}(10 \mu \mathrm{M})$ and different concentrations of NAA $(5,10$, and $50 \mu \mathrm{M})$ and collected at $6 \mathrm{~h}$ after treatments. Ovaries were treated by pollination and with NAA $(500 \mu \mathrm{M})$, GA3 $(3000 \mu \mathrm{M})$, CPPU $(400 \mu \mathrm{M})$, or BRs $(0.2 \mu \mathrm{M})$ at anthesis and collected at $6 \mathrm{~h}$ after treatments. Thirty 'EC1' plants and thirty ' $8419 \mathrm{~s}-1$ ' plants were used for fruit set and development analysis. Female flowers at the 12-15th node of the main stem were isolated to prevent pollen contamination on the day before anthesis, followed by treatment as above with bagging and pollination ('EC1' bagging represents the parthenocarpic fruit set process, '8419 s-1' bagging represents unpollination fruit abortion process, '8419 s-1' pollination represents pollinated fruit set process). The ovaries of the treated female flowers were harvested at $-3,-2$, $-1,0,1,2,3$ days post-anthesis (dpa). Non-treated leaves and fruit were used as controls. All samples were frozen in liquid nitrogen, and stored at $-80^{\circ} \mathrm{C}$ prior to analysis. Sampling was performed on three independent occasions.

Tomato plants (Solanum lycopersicum, cv MicroTom) were used in this study to generate CsTIR1 and CsAFB2 overexpression lines. The seeds of MicroTom were kindly provided by Professor Zhengguo Li (Genetic Engineering Research Center, Chongqing University, China). All tomato plants (10 plants per each line) were grown in an illuminated incubator under controlled conditions set as follows: $14 \mathrm{~h}$ day/10 h night cycle; $25 / 20^{\circ}$ $\mathrm{C}$ day/night temperature; $80 \%$ relative humidity and $250 \mu \mathrm{molm}^{-2} \mathrm{~s}^{-1}$ light intensity.

\section{Bioinformatics analysis of CSTIR1 and CSAFB2}

The cucumber genome database (http://cucumber.genomics.org.cn/page/cucumber/index.jsp) was searched for homologs of TIR1-like auxin receptors in cucumber using the AtTIR1 (AT3G62980.1) sequence. Blast searches revealed two cucumber genes (Csa001802 and Csa015043) with the highest similarity to AtTIR1, and two primer pairs were designed to amplify the fulllength cDNA sequences of these two genes using cDNA of cucumber fruits as a templates (Additional file 4). The PCR products were directly sequenced (Invitrogen) and sequence data were submitted to GenBank (accession number: GX901282 and GX901283). The MEGA program (version 5) was used for phylogenetic analysis with known TIR1-like auxin receptors based on homology. Structural domains were annotated using Smart (http://smart.emblheidelberg.de/) and illustrated using prosite (http:// 
prosite.expasy.org/mydomains/) with default parameters. GenBank accession numbers for the sequences analysis are listed in Additional file 5.

\section{Subcellular localization of CsTIR1-GFP and CsAFB2-GFP fusion protein}

The open reading frames of CsTIR1 and CsAFB2 were amplified and cloned into the pGreen0029 vector without the stop codon using specific primers (Additional file 4). Recombinant plasmids (pGreen 0029- CsTIR1GFP and pGreen 0029-CsAFB2-GFP) and a control plasmid with GFP alone were introduced into onion epidermal cells (obtained from Lab of Cucurbit Genetics and Germplasm Enhancement, Nanjing Agricultural University) using $1.0 \mu \mathrm{m}$ of gold microcarriers delivered via a pneumatic particle gun (Bio-Rad, PDS-1000/He, USA) with the following bombardment conditions: vacuum, $635 \mathrm{mmHg}$; helium pressure, $1100 \mathrm{psi}$; target distance, $6 \mathrm{~cm}$. After bombardment, onion epidermis cells were cultured on MS (Murashige and Skoog) medium for $14 \mathrm{~h}$ at $25{ }^{\circ} \mathrm{C}$ in darkness. The transformed cells were visualized using a confocal laser scanning microscope (Zeiss, LSM780, Germany).

\section{Generation of transgenic tomato plant lines}

The full-length sequences of CsTIR1 and CsAFB2 were amplified using gene specific primers (Additional file 4). Fragments of CsTIR1 and CsAFB2 were cloned into plp100 binary vector under the transcriptional control of the $35 S$ promoter. The constructs were then introduced into WT tomato plants (Solanum lycopersicum cv MicroTom) by Agrobacterium-mediated transformation [16]. The Agrobacterium (C58) was kindly provided by Professor Zhengguo Li (Genetic Engineering Research Center, Chongqing University, China). Transformed lines were selected on kanamycin $\left(50 \mathrm{mg} \mathrm{L}^{-1}\right)$ and further analyzed by qRT-PCR to confirm the presence of T-DNA inserts in the transgenic lines. For each construct, more than six independent lines with consistent phenotypes were obtained. Homozygous lines from the T2 generation were used for experiments.

\section{Electron microscopy}

Segments of leaves were collected from WT and transgenic plants after 6 weeks of growth on soil. Three replicates of each sample were mounted on aluminum stubs, sputtered with gold palladium for 30s, and examined under an S$3000 \mathrm{~N}$ scanning electron microscope (Hitachi, Japan).

Evaluation of parthenocarpy and seed germination assays To evaluate parthenocarpic fruit set rates of transgenic lines and WT plants, flower buds (5 plants per line) were emasculated $2 \mathrm{~d}$ before anthesis to prevent selfpollination. To guarantee equivalent growth conditions for parthenocarpic fruit, only seven flowers were kept per plant. The parthenocarpic fruit set rate was represented by the percentage of emasculated flowers that developed into fruit.

For seed germination assays, seeds were obtained and counted from WT and transgenic tomato lines (5 plants per line). The seeds were placed in petri dishes containing a layer of wet $3 \mathrm{~mm}$ filter paper (Whatman, China) and incubated in the dark at $25{ }^{\circ} \mathrm{C}$. The number of germinated seeds was counted after 3 days. The emergence of a radicle was considered as a germination event for the calculation of the percent germination. The experiment was replicated on three independent occasions with 25 seeds per replicate. All phenotypic data was listed in Additional file 6.

\section{Gene expression analysis}

All primers used for qRT-PCR and semi-quantitative RT-PCR are listed in Additional file 3. Total RNA was isolated using TRIzol reagent (Invitrogen, USA) and treated with DNase I (Fermentas, UK) according to the to manufacturer's instructions. First-strand cDNA was synthesized using the PrimeScript ${ }^{\mathrm{mm}}$ RT-PCR Kit (TaKaRa, Japan). Real-time quantitative RT-PCR was then carried out using the SYBR ${ }^{\circ}$ Premix Ex Taq ${ }^{\text {Tw }}$ Kit (TaKaRa, Japan) in a CFX96 multicolor real-time PCR detection system (Bio-Rad, USA). Sl-actin and Cs-actin were used as the internal control genes. For qRT-PCR analysis of Cs-miR393, U6 was used as internal control gene and the first-strand cDNA was synthesized using Mir-X miRNA First-Strand Synthesis Kit (TaKaRa, Japan). The qRT-PCR was carried out using the SYBR ${ }^{\circ}$ Premix Ex Taq ${ }^{\text {Ta }}$ II Kit (TaKaRa, Japan). Quantification of mRNA and miRNA levels was based on the comparative cycle threshold (CT) method and calculated as $2^{-\Delta \Delta C T}$. Analysis was conducted on the data from three independent reactions (technical replicates) using samples from three biological replicates. All CT values were listed in Additional file 7.

\section{Additional files}

Additional file 1: Fig. S1. Comparison of the predicted amino acid sequences of cucumber CsTIR1, CsAFB2 and AtTIR1, VvAFB2. (PDF $386 \mathrm{~kb}$ )

Additional file 2: Fig. S2. Quantitative PCR assession of positive transgenic tomato lines and detection of SITIR1 expression in transgenic tomato lines. (PDF $132 \mathrm{~kb}$ )

Additional file 3: Table S1. The oligonucleotide primer for QRT-PCR and semi-quantitative RT-PCR. (DOCX $14 \mathrm{~kb}$ )

Additional file 4: Table S2. List of primers used in construct preparation. (DOCX $15 \mathrm{~kb}$ )

Additional file 5: Table S3. Sequences from TIR-like F-box proteins of Embryophyte species used to generate the phylogenetic tree. (DOCX $15 \mathrm{~kb})$ 
Additional file 6: Table S4. Phenotypic data of Wild-type, CsTIR1-OE lines and CSAFB2-OE lines. (XLSX $10 \mathrm{~kb}$ )

Additional file 7: Table S5. $C T$ values of RT-PCR experiments conducted in this study. (XLSX $23 \mathrm{~kb}$ )

\section{Abbreviations}

6-BA: 6-benzylamino-purine; BRs: Brassinosteroids; CPPU: N-(2-chloro-4pyridyl)-N0-phenylurea, a diphenylurea-derived cytokinin; dpa: days post anthesis; GA3: Gibberellic acid; GFP: Green Fluorescent Protein; NAA: Naphthyl acetic acid; qRT-PCR: Quantitative real-time PCR

\section{Acknowledgements}

Not applicable.

\section{Funding}

This work was supported by the National Natural Science Foundation of China (NO: 31,430,075 and 31,672,168), the National Key Research and Development Program of China (2016YFD0101705), Special Fund for Agro-scientific Research in the Public Interest (NO: 201,403,032), National Key Research and Development Program of China (2016YFD0100204-25) and Jiangsu Agricultural Science and Technology Innovation Fund (No: CX(15)1019)

\section{Availability of data and materials}

Phylogenetic data generated and analyzed during the current study are available in the TreeBASE repository, [submission \#21182 for Fig. 1]. URLs to access Fig. 1 in TreeBASE is http://purl.org/phylo/treebase/phylows/study/ TB2:S21182.

All other datasets supporting the conclusions of this article are included within the article (and its Additional files).

\section{Authors' contributions}

JX and $J L$ contributed equally. JX and JL performed the experiments and drafted the manuscript. LC, TZ, ZW, PYZ, YJM and KJZ assisted with experimental procedures and data analysis. XOY and OFL supervised the experiments and assisted in writing and editing the manuscript. JFC conceived and designed the experiments, then revised the manuscript. All authors read and approved the final manuscript.

\section{Ethics approval and consent to participate}

Not applicable.

\section{Consent for publication}

Not applicable.

\section{Competing interests}

The authors declare that they have no competing interests.

\section{Publisher's Note}

Springer Nature remains neutral with regard to jurisdictional claims in published maps and institutional affiliations.

\section{Received: 6 March 2017 Accepted: 13 July 2017}

Published online: 26 July 2017

\section{References}

1. Dharmasiri N, Dharmasiri S, Estelle M. The F-box protein TIR1 is an auxin receptor. Nature. 2005;435(7041):441-5.

2. Kepinski S, Leyser $\mathrm{O}$. The Arabidopsis F-box protein TIR1 is an auxin receptor. Nature. 2005;435(7041):446-51.

3. Wang R, Estelle M. Diversity and specificity: auxin perception and signaling through the TIR1/AFB pathway. Curr Opin Plant Biol. 2014:21:51-8.

4. Korasick DA, Jez JM, Strader LC. Refining the nuclear auxin response pathway through structural biology. Curr Opin Plant Biol. 2015;27:22-8.

5. Salehin M, Bagchi R, Estelle M. SCFTIR1/AFB-based auxin perception: mechanism and role in plant growth and development. Plant Cell. 2015; 27(1):9-19.
6. Yu H, Zhang Y, Moss BL, Bargmann BOR, Wang RH, Prigge M, Nemhauser JL, Estelle M. Untethering the TIR1 auxin receptor from the SCF complex increases its stability and inhibits auxin response. Nat Plants. 2015;1(3):1-8.

7. Gray WM, Kepinski S, Rouse D, Leyser O, Estelle M. Auxin regulates SCF(TIR1)dependent degradation of AUX/IAA proteins. Nature. 2001;414(6861):271-6.

8. Dharmasiri N, Estelle M. Auxin signaling and regulated protein degradation. Trends Plant Sci. 2004;9(6):302-8.

9. Mockaitis K, Estelle M. Auxin receptors and plant development: a new signaling paradigm. Annu Rev Cell Dev Bi. 2008;24:55-80.

10. Gagne JM, Downes BP, Shiu SH, Durski AM, Vierstra RD. The F-box subunit of the SCF E3 complex is encoded by a diverse superfamily of genes in Arabidopsis. P Natl Acad Sci USA. 2002;99(17):11519-24.

11. Dharmasiri N, Dharmasiri S, Weijers D, Lechner E, Yamada M, Hobbie L, Ehrismann JS, Jurgens G, Estelle M. Plant development is regulated by a family of auxin receptor F box proteins. Dev Cell. 2005:9(1):109-19.

12. Parry G, Calderon-Villalobos LI, Prigge $M$, Peret $B$, Dharmasiri S, Itoh $H$, Lechner E, Gray WM, Bennett M, Estelle M. Complex regulation of the TIR1/ AFB family of auxin receptors. P Natl Acad Sci USA. 2009;106(52):22540-5.

13. Havens KA, Guseman JM, Jang SS, Pierre-Jerome E, Bolten N, Klavins E, Nemhauser JL. A synthetic approach reveals extensive Tunability of auxin signaling. Plant Physiol. 2012;160(1):135-42.

14. Walsh TA, Neal R, Merlo AO, Honma M, Hicks GR, Wolff K, Matsumura W, Davies JP. Mutations in an auxin receptor homolog AFB5 and in SGT1b confer resistance to synthetic picolinate auxins and not to 2,4dichlorophenoxyacetic acid or indole-3-acetic acid in arabidopsis. Plant Physiol. 2006;142(2):542-52.

15. Prigge MJ, Greenham K, Zhang Y, Santner A, Castillejo C, Mutka AM, O'Malley RC, Ecker JR, Kunkel BN, Estelle M. The Arabidopsis Auxin Receptor F-Box Proteins AFB4 and AFB5 Are Required for Response to the Synthetic Auxin Picloram. G3-Genes Genom Genet. 2016:6(5):1383-90.

16. Ren ZX, Li ZG, Miao Q, Yang YW, Deng W, Hao YW. The auxin receptor homologue in Solanum Lycopersicum stimulates tomato fruit set and leaf morphogenesis. J Exp Bot. 2011;62(8):2815-26.

17. Bian HW, Xie YK, Guo F, Han N, Ma SY, Zeng ZH, Wang JH, Yang YN, Zhu MY. Distinctive expression patterns and roles of the miRNA393/TIR1 homolog module in regulating flag leaf inclination and primary and crown root growth in rice (Oryza Sativa). New Phytol. 2012;196(1):149-61.

18. El-Sharkawy I, Sherif SM, Jones B, Mila I, Kumar PP, Bouzayen M, Jayasankar S. TIR1-like auxin-receptors are involved in the regulation of plum fruit development. J Exp Bot. 2014;65(18):5205-15.

19. El-Sharkawy I, Sherif S, El Kayal W, Jones B, Li Z, Sullivan AJ, Jayasankar S. Overexpression of plum auxin receptor PSITIR1 in tomato alters plant growth, fruit development and fruit shelf-life characteristics. BMC Plant Biol. 2016;16

20. Ren ZX, Wang XM. SITIR1 is involved in crosstalk of phytohormones, regulates auxin-induced root growth and stimulates stenospermocarpic fruit formation in tomato. Plant Sci. 2016;253:13-20.

21. Hendelman A, Buxdorf K, Stav R, Kravchik M, Arazi T. Inhibition of lamina outgrowth following Solanum Lycopersicum AUXIN RESPONSE FACTOR 10 (SIARF10) derepression. Plant Mol Biol. 2012;78(6):561-76.

22. MacAlister CA, Ohashi-lto K, Bergmann DC. Transcription factor control of asymmetric cell divisions that establish the stomatal lineage. Nature. 2007;445:537-40.

23. Pillitteri $L J$, Bogenschutz NL, Torii KU. The bHLH protein, MUTE, controls differentiation of stomata and the hydathode pore in Arabidopsis. Plant Cell Physiol. 2008:49:934-43.

24. Ohto MA, Floyd SK, Fischer RL, Goldberg RB, Harada JJ. Effects of APETALA2 on embryo, endosperm, and seed coat development determine seed size in Arabidopsis. Sex Plant Reprod. 2009;22(4):277-89.

25. Mizzotti C, Mendes MA, Caporali E, Schnittger A, Kater MM, Battaglia R, Colombo L. The MADS box genes SEEDSTICK and ARABIDOPSIS Bsister play a maternal role in fertilization and seed development. Plant J. 2012;70(3):409-20.

26. Auge GA, Perelman S, Crocco CD, et al. Gene expression analysis of lightmodulated germination in tomato seeds. New Phytol. 2009;183(2):301-14.

27. Navarro L, Dunoyer P, Jay F, Arnold B, Dharmasiri N, Estelle M, Voinnet O, Jones JDG. A plant miRNA contributes to antibacterial resistance by repressing auxin signaling. Science. 2006:312(5772):436-9.

28. Shu WB, Liu YL, Guo YH, Zhou HJ, Zhang J, Zhao ST, Lu MZ. A Populus TIR1 gene family survey reveals differential expression patterns and responses to 1-naphthaleneacetic acid and stress treatments. Front Plant Sci. 2015;6

29. Li J, Wu Z, Cui L, Zhang TL, Guo OW, Xu J, Jia L, Lou OF, Huang SW, Li ZG, Chen JF. Transcriptome comparison of global distinctive features between 
pollination and Parthenocarpic fruit set reveals transcriptional Phytohormone cross-talk in cucumber (Cucumis Sativus L.). Plant Cell Physiol. 2014;55(7):1325-42.

30. Cui L, Zhang T, Li J, Lou Q, Chen J. Cloning and expression analysis of Cs-TIR1/AFB2: the fruit development-related genes of cucumber (Cucumis sativus L.). Acta Physiologiae Plantarum. 2013.

31. Huang SW, Li RQ, Zhang ZH, Li L, Gu XF, Fan W, Lucas WJ, Wang XW, Xie BY, Ni PX, Ren YY, Zhu HM, Li J, Lin K, Jin WW, Fei ZJ, Li GC, Staub J, Kilian A, der Vossen EAG v, Wu Y, Guo J, He J, Jia ZQ, Ren Y, Tian G, Lu Y, Ruan J, Qian WB, Wang MW, Huang QF, Li B, Xuan ZL, Cao JJ, Asan WZG, Zhang JB, Cai QL, Bai YQ, Zhao BW, Han YH, Li Y, Li XF, Wang SH, Shi QX, Liu SQ, Cho WK, Kim JY, Xu Y, Heller-Uszynska K, Miao H, Cheng ZC, Zhang SP, Wu J, Yang YH, Kang HX, Li M, Liang HQ, Ren XL, Shi ZB, Wen M, Jian M, Yang HL, Zhang GJ, Yang ZT, Chen R, Liu SF, Li JW, Ma LJ, Liu H, Zhou Y, Zhao J, Fang XD, Li GQ, Fang L, Li YR, Liu DY, Zheng HK, Zhang Y, Qin N, Li Z, Yang GH, Yang S, Bolund L, Kristiansen K, Zheng HC, Li SC, Zhang XQ, Yang HM, Wang J, Sun RF, Zhang BX, Jiang SZ, Wang J, Du YC LSG. The genome of the cucumber, Cucumis sativus L. Nat Genet. 2009;41(12):1275-U1229.

32. Bowers JE, Chapman BA, Rong JK, Paterson AH. Unravelling angiosperm genome evolution by phylogenetic analysis of chromosomal duplication events. Nature. 2003;422(6930):433-8.

33. Cui LY, Wall PK, Leebens-Mack JH, Lindsay BG, Soltis DE, Doyle JJ, Soltis PS, Carlson JE, Arumuganathan K, Barakat A, Albert VA, Ma H. dePamphilis CW. Widespread genome duplications throughout the history of flowering plants. Genome Res. 2006;16(6):738-49.

34. Tan X, Calderon-Villalobos LIA, Sharon M, Zheng CX, Robinson CV, Estelle M, Zheng N. Mechanism of auxin perception by the TIR1 ubiquitin ligase. Nature. 2007:446(7136):640-5.

35. Rutitzky M, Ghiglione H, Curá J, Casal J, Yanovsky M. Comparative genomic analysis of light-regulated transcripts in the Solanaceae. BMC Genomics. 2009;10:60-73

36. Vidal EA, Araus V, Lu C, Parry G, Green PJ, Coruzzi GM, Gutierrez RA. Nitrateresponsive miR393/AFB3 regulatory module controls root system architecture in Arabidopsis Thaliana. P Natl Acad Sci USA. 2010;107(9):4477-82.

37. Chen ZH, Bao ML, Sun YZ, Yang YJ, Xu XH, Wang JH, Han N, Bian HW, Zhu MY. Regulation of auxin response by miR393-targeted transport inhibitor response protein 1 is involved in normal development in Arabidopsis. Plant Mol Biol. 2011;77(6):619-29.

38. Li X, Xia KF, Liang Z, Chen KL, Gao CX, Zhang MY. MicroRNA393 is involved in nitrogen-promoted rice tillering through regulation of auxin signal transduction in axillary buds. Sci Rep-Uk. 2016;6

39. Pinweha N, Asvarak T, Viboonjun U, Narangajavana J. Involvement of miR160/miR393 and their targets in cassava responses to anthracnose disease. J Plant Physiol. 2015;174:26-35.

40. Xia KF, Wang R, Ou XJ, Fang ZM, Tian CG, Duan J, Wang YQ, Zhang MY. OsTIR1 and OsAFB2 downregulation via OsmiR393 overexpression leads to more tillers, early flowering and less tolerance to salt and drought in Rice. PLoS One. 2012:7(1):364-73.

41. Chen ZH, Hu LZ, Han N, Hu JQ, Yang YJ, Xiang TH, Zhang XJ, Wang LL. Overexpression of a miR393-resistant form of transport inhibitor response protein 1 (mTIR1) enhances salt tolerance by increased osmoregulation and $\mathrm{Na}+$ exclusion in Arabidopsis Thaliana. Plant Cell Physiol. 2015;56(1):73-83.

\section{Submit your next manuscript to BioMed Central and we will help you at every step:}

- We accept pre-submission inquiries

- Our selector tool helps you to find the most relevant journal

- We provide round the clock customer support

- Convenient online submission

- Thorough peer review

- Inclusion in PubMed and all major indexing services

- Maximum visibility for your research

Submit your manuscript at www.biomedcentral.com/submit

) Biomed Central 